\title{
ANALISIS FAKTOR-FAKTOR KONSUMSI MINUMAN KERAS (TUAK PAHIT) PADA REMAJA DI DESA BUNTU TABANG KECAMATAN GANDASIL KABUPATEN TANA TORAJA
}

\author{
Imran Sukiman, Syarifuddin, Ilham Willem \\ (Program Studi Kesehatan Masyarakat Fakultas Ilmu Kesehatan Universitas Muhammadiyah \\ Parepare) \\ (imransukiman020894@gmail.com)
}

\begin{abstract}
ABSTRAK
Minuman keras adalah minuman yang mengandung etanol. Etanol adalah bahan psikoaktif dan konsumsinya menyebabkan penurunan kesadaran. Minuman keras (miras) adalah seluruh jenis minuman yang mengandung zat adiktif (alkohol). Alkohol adalah obat psikoaktif yang paling banyak digunakan. Lebih dari 13 juta orang menganggap dirinya pecandu alkohol (alkoholic). Fenomena penggunaan minuman keras di kalangan remaja dan orang dewasa semakin meningkat. Tujuan penelitian ini adalah untuk menganalisis faktor-faktor konsumsi minuman keras (tuak pahit) pada remaja di desa buntu tabang kecamatan gandasil kabupaten tana toraja. Jenis penelitian ini adalah deskriptif yaitu penelitian yang menggambarkan bagaimana tingkat perilaku, pelayanan kesehatan dan faktor lingkungan remaja yang mengkomsumsi minuman keras (tuak pahit). Sampel dalam penelitian ini adalah 37 anak remaja yang berusia 15-25 tahun, Teknik pengambilan sampel yang digunakan yaitu Total Sampling dimana jumlah sampel sama dengan jumlah populasi. Berdasarkan hasil penelitian yang telah dilakukan bahwa pada Remaja di Desa Buntu Tabang Kecamatan Gandasil Kabupaten Tana Toraja mengkonsumsi minuman keras (tuak pahit) karena dipengaruhi oleh faktor lingkungan dimana hasil penelitian ini menunjukkan kategori yang mendukung yaitu sebanyak 22 orang $(59,5 \%)$, menurut jenis perilaku masuk dalam kategori yang mendukung yaitu sebanyak 22 orang $(59,5 \%)$. Sedangkan kategori pelayanan kesehatan yang kurang baik sebanyak $19(51,3 \%)$.
\end{abstract}

Kata kunci : Tuak pahit, remaja

\section{ABSTRACT}

Liquor is a drink containing ethanol. Ethanol is a psychoactive substance and its consumption causes loss of consciousness. Liquors (alcoholic beverages) are all types of drinks that contain addictive substances (alcohol). Alcohol is the most widely used psychoactive drug. More than 13 million people consider themselves alcoholics. The phenomenon of the use of liquor among teenagers and adults is increasing. The purpose of this study was to analyze the factors of consumption of liquor (bitter tuak) in adolescents in the village of Buntu Tabang, Gandasil District, Tana Toraja Regency. This type of research is descriptive, namely research that describes how the level of behavior, health services and environmental factors of adolescents who consume liquor (bitter tuak). The sample in this study were 37 adolescents aged 15-25 years. The sampling technique used was total sampling where the number of samples was the same as the population. Based on the results of research that has been carried out that in adolescents in Buntu Tabang Village, Gandasil District, Tana Toraja Regency consume liquor (bitter tuak) because it is influenced by environmental factors where the results of this study indicate a supportive category of 22 people (59.5\%), according 
types of behavior fall into the supporting category of 22 people (59.5\%). While the category of poor health services was $19(51.3 \%)$.

Keywords: bitter tuak, teenagers 


\section{PENDAHULUAN}

Masa remaja dalam kehidupan seharihari sangat berkaitan erat dengan aspek psikologi yang menjadikan remaja sering mancoba sesuatu untuk alasan mencari jati diri. Kadang remaja salah mengartikan jati diri sehingga terjebak dalam pergaulan bebas terutama terjebak dalam hal penggunaan minuman keras, selain faktor rasa ingin mencoba faktor lingkungan atau pergaulan juga dapat mempengaruhi keingintahuan remaja tentang minuman keras jadi pengaruh perubahan psikologi dapak berdampak pada penggunaan minuman keras pada masa remaja.

Minuman keras (miras) adalah seluruh jenis minuman yang mengandung zat adiktif (alkohol). Alkohol adalah obat psikoaktif yang paling banyak digunakan. Lebih dari 13 juta orang menganggap dirinya pecandu alkohol (alkoholic). Fenomena penggunaan minuman keras di kalangan remaja dan orang dewasa semakin meningkat. Menurut laporan World Health Organization (WHO) pada tahun 2012 terdapat 2,5 juta penduduk dunia meninggal akibat mengkonsumsi minuman keras. Sebesar sembilan persen angka kematian tersebut terjadi pada orang muda berusia 15 - 29 tahun. Di Indonesia tahun 2012 sebagian besar korban penyalahgunaan minuman keras adalah remaja yang terbagi dalam golongan umur 14 16 tahun (47,7\%), golongan umur 17 - 20 tahun (51\%), dan golongan umur $21-22$ tahun $(31 \%)$. Berdasarkan hasil survei Dinas Penelitian dan Pengembangan POLRI memperlihatkan bahwa pemakaian narkotika dan minuman keras di Indonesia terbanyak dari golongan pelajar baik SLTP/SLTA ${ }^{1}$.

Masyarakat yang mengatakan bahwa dengan minum minuman keras kepercayaan diri mereka bertambah dari yang pemalu menjadi pemberani, mereka beranggapan bahwa semua masalah dapat teratasi dengan minum minuman keras, minuman keras dapat memperbanyak teman. Mengkonsumsi minuman keras adalah salah satu bentuk perilaku yang dianggap menyimpangan bila sudah berlebihan. Perilaku menyimpang yang terjadi di kalangan masyarakat tidak akan begitu saja muncul apabila tidak ada faktor penarik atau faktor pendorong. Faktor penarik berada di luar diri seseorang, sedangkan faktor pendorong berasal dari dalam diri atau keluarga yang memungkinkan seseorang untuk melakukan penyimpangan tersebut ${ }^{2}$.

Dampak minuman keras telah terbukti menjadi penyebab dari berbagai penyakit. Dari penyakit yang sederhana sampai yang sangat berbahaya seperti liver akan merusak jaringan hati gangguan penyerapan zat makanan dan mengakibatkan kurang gizi, meningkatkan tekanan darah membuat denyut jantung menjadi tidak normal. Terhadap otak bisa mengakibatkan hilangnya pengendalian diri, membuat sempoyongan, mengganggu kemampuan berbicara, menurunkan 
kemampuan intelektual, mengakibatkan hilangnya ingatan (blockout) menyebabkan terjadinya amnesia dan merusak jaringan saraf. Kerusakan urat saraf atau yang disebut polyneuropathy lain juga berhubungan dengan sakit radang kantong perut dan pengerasan pada bagian hati ${ }^{3}$.

\section{BAHAN DAN METODE}

Jenis penelitian yang digunakan adalah penelitian deskriptif yaitu penelitian yang menggambarkan bagaimana tingkat perilaku, pelayanan kesehatan dan faktor lingkungan remaja yang mengkomsumsi minuman keras (tuak pahit). Penelitian ini bertepatan di Desa Buntu Tabang Kecamatan Gandasil Kabupaten Tana Toraja. Waktu pelaksanaan peneliti ini mulai bulan Mei sampai bulan Juni Tahun 2018. Populasi dalam penelitian ini adalah anak remaja lakilaki di Desa Buntu Tabang Kecamatan Gandasil Kabupaten Tana Toraja 37 remaja usia 15-25 tahun. Sampel dalam penelitian ini adalah 37 anak remaja laki-laki usia 15-25 tahun di Desa Buntu Tabang Kecamatan Gandasil Kabupaten Tana Toraja. Analisis data yang di gunakan dalam penelitian ini :

$P=\frac{f o}{N} \times 100 \%$

Keterangan:

$\mathrm{P}=$ Persentasi pertanyaan yang dijawab

fo $=$ Frekuensi jawaban

$\mathrm{N}$ = Jumlah Responden

$\%=$ Persentase Jawaban
HASIL

Hasil penelitian menunjukkan distribusi responden yang mengkonsumsi minuman keras dengan klasifikasi umur, pendidikan, pekerjaan, dan lama komsumsi tuak pahit. di Desa Buntu Tabang Kecamatan Gandasil Kabupaten Tana Toraja yang berumur 15-20 tahun dengan persentase 48,6 $\%$ sedangkan yang berumur 20-25 tahun dengan persentase $51,4 \% \%$. pendidikan responden yang mengkomsumsi minuman keras (tuak pahit) yang tidak sekolah sebanyak 13 orang dengan persentase $35,1 \%$, SMP sebanyak 3 orang dengan persentase $8,1 \%$, SMA sebanyak 9 orang dengan persentase 24,3 dan perguruan tinggi sebanyak 12 orang dengan persentase 32,5. Pekerjaan responden yang mengkomsumsi minuman keras (tuak pahit) yang tukang sebanyak 10 orang dengan persentase $27,1 \%$, perani sebanyak 17 orang dengan persentase $45,9 \%$ dan pengangguran sebanyak 10 orang dengan persentase $27,1 \%$. Lama komsumsi responden selama 1 tahun sebanyak 15 orang dengan persentase $40,6 \%$, 2 tahun sebanyak 10 orang dengan persentase $27,1 \%$ dan 3 tahun sebanyak 12 orang dengan persentase $32,5 \%$.

Distribusi responden yang mengkonsumsi minuman keras dengan faktor lingkungan sosial, faktor perilaku remaja dan faktor pelayanan kesehatan menunjukkan bahwa 37 responden, indikator penilaian terhadap faktor lingkungan yang mempengaruhi remaja mengkonsumsi 
minuman keras (tuak pahit), dimana kategori yang mendukung yaitu sebanyak 22 orang (59,5\%), kurang mendukung sebanyak 13 orang $(35,1 \%)$ sedangkan kategori yang tidak mendukung sebanyak $2(5,4 \%)$. indikator penilaian terhadap perilaku remaja yang mengkonsumsi minuman keras (tuak pahit), dimana perilaku remaja yang dikategorikan baik yaitu sebanyak 7 orang $(18,9 \%)$, cukup baik sebanyak 13 orang $(35,2 \%)$ sedangkan kategori yang kurang baik sebanyak 17 (45,9\%). Dan indikator penilaian terhadap pelayanan kesehatan yang mengkonsumsi minuman keras (tuak pahit), dimana pelayanan kesehatan yang dikategorikan baik yaitu sebanyak 8 orang $(21,6 \%)$, cukup baik sebanyak 10 orang $(27,1 \%)$ sedangkan kategori yang kurang baik sebanyak 19 $(51,3 \%)$.

\section{PEMBAHASAN}

Minuman keras saat ini merupakan permasalahan yang cukup berkembang di dunia remaja dan menunjukkan kecenderungan yang meningkat setiap tahunnya yang akibatnya dirasakan dalam bentuk kenakalan-kenakalan, perkelahian, serta munculnya geng- geng remaja, perbuatan asusila, dan maraknya premanisme pada kalangan remaja. Masalah penyalahgunaan minuman keras adalah masalah pemeliharaan kesehatan mental. Sekarang ini penyalahgunaan minuman keras pada remaja semakin banyak yang dipengaruhi beberapa faktor missal : lingkungan, stres, coba-coba dan lain-lain.

Hasil penelitian di Desa Buntu Tabang Kecamatan Gandasil Kabupaten Tana Toraja bahwa perilaku masyarakat tentang minuman keras erat kaitannya dengan kondisi lingkungan, yang meliputi kondisi lingkungan sosial budaya antara lain adanya faktor kebiasaan meminum minuman keras, adanya faktor pergaulan baik dengan teman maupun dilingkungan kerja, adanya faktor ingin tubuh untuk mencoba minuman keras, serta kondisi lingkungan fisik seperti cuaca dingin.

Tabel 1 tersebut menunjukkan bahwa umur responden yang mengkonsumsi minuman keras (Tuak Pahit) di Desa Buntu Tabang Kecamatan Gandasil Kabupaten Tana Toraja yang berumur 15-20 tahun dengan persentase $48,6 \%$ sedangkan yang berumur 20-25 tahun dengan persentase $51,4 \% \%$. Hal ini disebabkan pada umur tersebut ketahanan tubuh pada responden masih stabil dan rasa penasaran juga pada remaja tinggi. pendidikan responden yang mengkomsumsi minuman keras (tuak pahit) yang tidak sekolah sebanyak 13 orang dengan persentase $35,1 \%$, SMP sebanyak 3 orang dengan persentase $8,1 \%$, SMA sebanyak 9 orang dengan persentase 24,3 dan perguruan tinggi sebanyak 12 orang dengan persentase 32,5 , hal ini di sebabkan pendidikan yang rendah dan pengaruh lingkungan atau tradisi sehingga menyebabkan tinngginya remaja yang mengkomsumsi tuak pahit tersebut. 
Pekerjaan responden yang mengkomsumsi minuman keras (tuak pahit) yang tukang sebanyak 10 orang dengan persentase $27,1 \%$, perani sebanyak 17 orang dengan persentase $45,9 \%$ dan pengangguran sebanyak 10 orang dengan persentase $27,1 \%$, hal ini sebabkan karena pada pekerja yang mengkomsumsi tua pahit akan menambah stamina sehingga dalam bekerja tidak mudah lelah. Lama komsumsi responden selama 1 tahun sebanyak 15 orang dengan persentase $40,6 \%, 2$ tahun sebanyak 10 orang dengan persentase $27,1 \%$ dan 3 tahun sebanyak 12 orang dengan persentase $32,5 \%$, hal ini di sebabkan lamanya remaja mengkomsumsi tuak pahit karna menurut mereka tuak pahit tersebut sudah menjadi minuman keseharian.

$$
\text { Pekerjaan responden yang }
$$

mengkomsumsi minuman keras (tuak pahit) yang tukang sebanyak 10 orang dengan persentase $27,1 \%$, petani sebanyak 17 orang dengan persentase $45,9 \%$ dan pengangguran sebanyak 10 orang dengan persentase $27,1 \%$, hal ini sebabkan karena pada pekerja yang mengkomsumsi tua pahit akan menambah stamina sehingga dalam bekerja tidak mudah lelah. Lama komsumsi responden selama 1 tahun sebanyak 15 orang dengan persentase 40,6\%, 2 tahun sebanyak 10 orang dengan persentase $27,1 \%$ dan 3 tahun sebanyak 12 orang dengan persentase $32,5 \%$, hal ini di sebabkan lamanya remaja mengkomsumsi tuak pahit karna menurut mereka tuak pahit tersebut sudah menjadi minuman keseharian.
Tabel 2 menunjukkan indikator penilaian

terhadap faktor lingkungan yang mempengaruhi remaja mengkonsumsi minuman keras (tuak pahit), dimana kategori yang mendukung yaitu sebanyak 22 orang (59,5\%), kurang mendukung sebanyak 13 orang $(35,1 \%)$ sedangkan kategori yang tidak mendukung sebanyak $2(5,4 \%)$

Hasil penelitian ini menunjukkan mayoritas remaja di Desa Buntu Tabang Kecamatan Gasndasil Kabupaten Tana Toraja menyatakan bahwa faktor lingkungannya sangat berpengaruh sehingga para remaja mengkonsumsi minuman keras (tuak pahit). Karena Lingkungan dapat memberikan pengaruh pertama bagi seseorang dimana seseorang dapat mempelajari hal yang baik dan juga hal buruk tergantung pada sifat yang ada disekitarnya. Mereka meminum minuman keras pada dasarnya berawal dari ingin mencoba sendiri dan dari pergaulan sesama teman ditingkat lingkungan rumah dan di tempat kerja.

Selain itu, dari 37 responden diantaranya ada beberapa responden yang mengkonsumsi minuman keras karena 
keluarganya tidak melarang terutama orang tua, juga karena minum-minuman keras di lingkungannya itu sudah dianggap biasa oleh masyarakat dan mereka merasa hal tersebut wajar dilakukan dalam adat istiadat serta adanya ajakan dari teman pergaulan.

Tabel 2 menunjukkan bahwa dari 37 responden, indikator penilaian terhadap perilaku remaja yang mengkonsumsi minuman keras (tuak pahit), dimana perilaku remaja yang dikategorikan baik yaitu sebanyak 7 orang $(18,9 \%)$, cukup baik sebanyak 13 orang $(35,2 \%)$ sedangkan kategori yang kurang baik sebanyak 17 (45,9\%).

Hasil penelitian ini menunjukkan bahwa mayoritas remaja di Desa Buntu Tabang Kecamatan Gandasil Kabupaten Tana Toraja mengkonsumsi minuman keras (tuak pahit) karena dipengaruhi juga oleh perilaku masyarakat disana. Perilaku yang didasarkan oleh akan lebih baik daripada perilaku yang tidak didasari oleh pengetahuan karena Pengetahuan merupakan domain yang sangat penting dalam membentuk perilaku atau tindakan seseorang.

Perilaku remaja mengkonsumsi minuman keras karena adanya rasa penasaran dan keingintahuan yang besar sehingga mendorong remaja untuk melakukan perilaku demikian. Kemudian mereka menunjukkan identitas diri dengan minuman keras karena dianggap tidak modern oleh teman sebaya jika tidak mengkonsumsi minuman keras.

Tabel 2 menunjukkan bahwa dari 37 responden, indikator penilaian terhadap pelayanan kesehatan yang mengkonsumsi minuman keras (tuak pahit), dimana pelayanan kesehatan yang dikategorikan baik yaitu sebanyak 8 orang $(21,6 \%)$, cukup baik sebanyak 10 orang $(27,1 \%)$ sedangkan kategori yang kurang baik sebanyak 19 $(51,3 \%)$.

Hasil penelitian ini menunjukkan bahwa pelayanan kesehatan yang ada di Desa Buntu Tabang Kecamatan Gandasil Kabupaten Tana Toraja sepenuhnya belum berhasil dikarenakan masih banyaknya remaja yang mengkonsumsi minuman keras (tuak pahit) dan tentunya pelayanan kesehatan di masyarakat sangat berpengaruh terhadap pengetahuan para remaja tentang bahaya mengkonsumsi minuman keras.

Pendapat responden mengenai pelayanan kesehatan disana yaitu belum pernah diadakannya penyuluhan mengenai minuman keras sehingga masih banyaknya remaja terutama yang tidak sekolah dan yang masih berpendidikan SMP dan SMA tidak mengetahui apa dampak dan akibat dari keseringan mengkonsumsi minuman keras (tuak pahit).

Masyarakat disana mengonsumsi tuak bukan karena faktor ketagihan, tetapi mereka mengonsumsi hanya karena faktor keterbiasaan. Mengonsumsi tuak sudah 
merupakan budaya yang sangat melekat pada diri masyarakat Desa Buntu Tabang jadi kebiasaan tersebut sangat sulit untuk dihilangkan. Tuak selalu disajikan disetiap perayaan pesta adat yaitu pada perayaan pesta adat Rambu solo' dan Rambu tuka'. Akan tetapi, tuak paling sering disajikan pada saat perayaan Rambu solo' karena acara tersebut merupakan pesta adat terbesar di Toraja. Selain itu, masyarakat juga banyak yang datang ke perayaan pesta adat tersebut. Jika dilihat dari segi kebiasaan mengonsumsi tuak, setiap orang bebas untuk mengonsumsi tanpa dipengaruhi oleh status sosial ekonomi masyarakat, serta tidak ada larangan untuk meminum tuak bagi siapa pun yang ingin mengonsumsinya, termasuk anak-anak dan para kaum perempuan.

Masyarakat di Desa Buntu Tabang Kecamatan Gandasil Kabupaten Tana Toraja yang memiliki kebudayaan dan tradisi yang masih kental sehingga mempengaruhi perilaku remaja setempat dan bagi mereka mengkonsumsi minuman keras adalah suatu hal yang biasa-biasa saja. Dan kebiasaan tersebut juga sering dilakukan bersama tokohtokoh masyarakat karena hal tersebut menjadi suatu kebiasaan terutama pada saat perayaan pesta adat. Tidak adanya peraturan mengenai larangan mengkonsumsi minuman keras di daerah tersebut karena hal ini merupakan salah satu kebudayaan masyarakat disana. Begitupun dengan petugas pelayanan kesehatan disana yang sangat kesulitan untuk mengadakan penyuluhan untuk merubah kebiasaan dan pola pikir masyarakat

\section{KESIMPULAN DAN SARAN}

Berdasarkan penelitian dan analisis yang telah dilakukan maka dapat ditarik kesimpulan sebagai berikut, Remaja di Desa Buntu Tabang Kecamatan Gandasil Kabupaten Tana Toraja mengkonsumsi minuman keras (tuak pahit) karena dipengaruhi oleh faktor lingkungan dengan dimana hasil penelitian ini menunjukkan kategori yang mendukung yaitu sebanyak 22 orang (59,5\%). Dengan alasan menambah stamina dalam bekerja serta alasan orang tua yang tidak melarang. Berdasarkan penelitian ini menunjukkan bahwa perilaku remaja di Desa Buntu Tabang Kecamatan Gandasil Kabupaten Tana Toraja masuk dalam kategori yang kurang baik sebanyak 17 (45,9\%). Dengan alasan remaja yang tidak mengkonsumsi tuak pahit dianggap tidak modern oleh teman sebayanya. Selain itu juga remaja yang mengkonsumsi tuak pahit salah satu kurangnya perhatian dari orang tua. Hasil penelitian ini menunjukkan bahwa pelayanan kesehatan yang ada di Desa Buntu Tabang Kecamatan Gandasil Kabupaten Tana Toraja sepenuhnya belum berhasil dikarenakan masuk dalam kategori kurang baik sebanyak 19 (51,3\%). Dengan alasan penyuluhan pelayanan kesehatan sebelumnya tidak menyampaikan bahaya tuak pahit waktu diadakannya penyuluhan serta pelayanan 
kesehatan tidak mengeluarkan aturan dilarang mengkonsumsi tuak pahit. Disarankan kepada Pemerintah setempat sebaiknya lebih sering melakukan pertemuan bersama masyarakat dan tokoh masyarakat sebagai salah satu upaya pendekatan agar masyarakat lebih mudah menerima kebijakan mengenai pengendalian perilaku konsumsi minuman keras yang akan dikeluarkan. Bagi Puskesmas petugas kesehatan setempat secara aktif memberikan sosialisasi dalam bentuk penyuluhan kepada masyarakat mengenai informasi tentang dampak dan akibat konsumsi tuak pahit secara komprehensif, dari sisi tradisi, agama dan kesehatan. Dan bagi masyarakat meningkatkan pengawasan terhadap remaja agar tidak terjerumus dalam pergaulan pengkonsumsi minuman keras. Perlu di lakukannya penyuluhan tentang dampak yang di timbulkan oleh konsumsi minuman beralkohol terhadap remaja, baik dari segi kesehatan, hukum dan keagamaan. Bagi Remaja diharapkan agar dapat mengubah cara berpikir yang salah dan mengubah persepsi yang irasional menjadi yang rasional dan tidak tergantung pada hal-hal yang negatif.

\section{DAFTAR PUSTAKA}

1. Wulan. Analisis Komsumsi Tuak Pahit pada Peminum Tuak di Desa Lumban Siagian Jae Kabupaten Tapanuli Kecamatan Siatas Barita Kabupaten Utara
Sumatra Utara. 2013.[Diakses tanggal 19

Oktober 2018]

2. Waluya. Gambaran Peminum Tuak (Study Kasus pada Warga Sawere Desa Bontoraja Kecamatan Gantarang Kabupaten Bulukumba). 2012. [Diakses tanggal 21 November 2018]

3. Rusdi Rahman. Perilaku Remaja Pengguna Miras (Studi di Desa Buakkang Kecamatan Bungaya kabupaten Gowa). 2016. [diakses tanggal 15 Oktober 2018]

4. Binham, "Masalah Minuman Keras Dikalangan Remaja”. https://binham.wordpress.com/2012/10/1

1/mengatasi-masalah-minuman keras/.Diakses pada tanggal 16 Desember 2017 pada Pukul 11.30

5. Gunarsa, Ny. Singgih D. Psikologi Remaja. Jakarta: Gunung Mulia; 2003.

6. Hurlock E. Psikologi Perkembangan, Suatu Pendekatan Sepanjang Rentang Kehidupan (ed 5). Jakarta: Erlangga; 1992.

7. King, Laura K. Psikologi Umum. Jakarta: Salemba Humanika; 2012.

8. Muku, Sukadana. 2009. Pengaruh Rasio Kompresi terhadap Unjuk Kerja Mesin Empat Langkah Menggunakan Arak Bali sebagai Bahan Bakar. Jurnal Ilmiah Teknik Mesin Cakra M, April. . 2012; Volume 3 hal. 26-32.

9. Notoatmodjo. Metodologi PenelitianKesehatan. Jakarta: Rinekacipta; 2010. 
10. Noviyanti, Rizki. 2014. Pengaruh Konsumsi Minuman Tuak Terhadap Erosi Gigi di Kecamatan Maiwa Kabupaten Enrekang. Fakultas Kedokteran Gigi. UNHAS.

11. Nursalam. Konsep dan Metodologi keperawatan (ed. 2). Jakarta: Salemba Medika; 2011.

12. Paring W, U. "Tradisi Tuak dan Peran Perempuan Tuban", http://srinthil.org/69/tradisi-tuak-danPeran-Perempuan-Tuban/Diakses pada tanggal 16 Desember 2017 Jam 23.10

13. Ridwanaz. "Jurnal Kesehatan Pengertian Mabuk dan Jenis Minuman Beralkohol”. http://ridwanaz.com/Kesehatan/Pengertia
n-Mabuk-dan-Jenis-Minuman

Beralkohol/Diakses pada tanggal 16 Desember 2017 jam 10.55

14. Sarwono S.W. Psikologi Remaja. Edisi Revisi. Cetakan XIV. Jakarta. Rajawali Pers; 2011.

15. Sinda F, Len. Peranan Kulit Kayu Buli Sonneratio Sp. Dalam Fermentasi Nira Aren Menjadi Minuman Beralkohol. Marina Chimica Acta. 2003; April. Volume 1.

16. Sofia, A. Adiyanti, M. G. Hubungan Pola Asuh Otoritatif Orang Tua dan Konformitas Teman Sebaya Terhadap Kecerdasan Moral; 2013. 


\section{LAMPIRAN}

Tabel 1 Distribusi responden yang mengkonsumsi minuman keras dengan klasifikasi umur, pendidikan, pekerjaan, dan lama komsumsi tuak pahit. di Desa Buntu Tabang

Kecamatan Gandasil Kabupaten Tana Toraja, dilihat pada tabel di bawah :

\begin{tabular}{ccc}
\hline Umur & frekuensi & Persentase (\%) \\
\hline $15-20$ tahun & 18 & 48,6 \\
$20-25$ tahun & 19 & 51,4 \\
\hline Total & 37 orang & 100 \\
\hline Pendidikan & frekuensi & Persentase (\%) \\
\hline Tidak sekolah & 13 & 35,1 \\
SMP & 3 & 8,1 \\
SLTP & 9 & 24,3 \\
Perguruan tinggi & 12 & 32,5 \\
\hline Total & 37 orang & 100 \\
\hline Pekerjaan & frekuensi & Persentase (\%) \\
\hline Tukang & 10 & 27,1 \\
Petani & 17 & 45,9 \\
Pengngguran & 10 & 27,1 \\
\hline Total & 37 orang & 100 \\
\hline lama kunsumsi tuak pahit & frekuensi & Persentase (\%) \\
\hline 1 tahun & 15 & 40,6 \\
2 tahun & 10 & 27,1 \\
3 tahun & 12 & 32,5 \\
\hline Total & 37 orang & 100
\end{tabular}

Tabel 2. Distribusi responden yang mengkonsumsi minuman keras dengan faktor lingkungan sosial, faktor perilaku remaja dan faktor pelayanan kesehatan di Desa Buntu Tabang Kecamatan Gandasil Kabupaten Tana Toraja.

\begin{tabular}{ccc}
\hline Faktor lingkungan sosial & frekuensi & persentase \\
\hline Mendukung & 22 & 59,5 \\
Kurang mendukung & 13 & 35,1 \\
Tidak mendukung & 2 & 5,4 \\
\hline Total & 37 orang & 100 \\
\hline Faktor perilaku remaja & frekuensi & persentase \\
\hline Baik & 7 & 18,9 \\
Cukup baik & 13 & 35,2 \\
Kurang baik & 17 & 45,9 \\
\hline Total & 37 orang & 100 \\
\hline Faktor pelayanan & frekuensi & persentase \\
kesehatan & & \\
\hline Baik & 8 & 21,6 \\
Cukup baik & 10 & 27,1 \\
Kurang baik & 19 & 51,3 \\
\hline
\end{tabular}

